\title{
Effective harvesting of photons for improvement of solar energy conversion by graded bandgap multilayer solar cells
}

\author{
I.M. Dharmadasa ${ }^{1 *}$, N.D.P.S.R. Kalyanaratne ${ }^{2}$ and R. Dharmadasa ${ }^{3}$ \\ ${ }^{1}$ Materials and Engineering Research Institute, Sheffield Hallam University, Sheffield S1 1WB, UK. \\ ${ }^{2}$ Department of Electrical Engineering, Faculty of Engineering, University of Moratuwa, Moratuwa. \\ ${ }^{3}$ Department of Chemistry, Loughborough University, Loughborough LE11 3TU, UK.
}

\begin{abstract}
Various ways to harvest photons in the solar spectrum and heat energy from the surroundings have been considered by utilizing solid state physics principles. A graded bandgap multi-layer solar cell has been designed to absorb UV, visible and infrared radiation, and to combine impact-ionization and impurity photovoltaic (PV) effect to enhance photo-generation of charge carriers and the collection. The above theoretical concepts were experimentally tested using the well researched material system, $\mathrm{GaAs} / \mathrm{Al}_{\mathrm{x}} \mathrm{Ga}_{(1-\mathrm{x})} \mathrm{As}$. The highest reported $\mathrm{V}_{\mathrm{oc}} \sim 1175 \mathrm{mV}$ together with the highest possible fill factors (FFs) in the mid $80 \%$ 's, have been achieved for the initial devices. The overall efficiency achieved using only two growths is $\sim 20 \%$. As expected from the initial design, the impurity PV effect is experimentally observed producing $\mathrm{V}_{\mathrm{oc}}$ values in the range of 650-900 $\mathrm{mV}$ under complete darkness for the GaAs/ $\mathrm{Al}_{\mathrm{x}} \mathrm{Ga}_{(1-\mathrm{x})} \mathrm{As}$ based devices. Both the theoretical concepts and experimental results are presented in this paper.
\end{abstract}

Keywords: Graded bandgap, next generation solar cells, photon harvesting, solar cells.

\section{INTRODUCTION}

Solar energy conversion is at the top of the list of renewable energy technologies, but the high initial cost still remains the main barrier for the full realization of its potential. The two most important factors to reduce the cost are (i) improvement of the solar to electric conversion efficiency and (ii) the use of low cost materials and manufacturing techniques to produce solar cells.

Traditionally, solar energy conversion is carried out using two different methods; the utilization of UV and visible photons in photovoltaic (PV) devices and infrared
(IR) photons or heat energy in solar thermal collectors. In order to reduce the cost, it is important to design devices, which can absorb all three types of photons (UV, visible and IR) in one device. It is also possible to combine other related processes such as impact ionization and impurity PV effect within the same device in order to enhance photo-generation and collection of charge carriers and hence increase the conversion efficiency. This paper addresses how to enhance conversion efficiency by effectively harvesting the available photons using a PV solar cell.

The conversion efficiency $(\eta)$ of a PV solar cell is given by the expression:

$$
\eta=\frac{V_{o c} \cdot J_{s c} \cdot F F}{P_{i n}}
$$

where $\mathrm{V}_{\mathrm{oc}}$ is the open circuit voltage, $\mathrm{J}_{\mathrm{sc}}$ is the short circuit current density, FF is the fill factor or the curve factor and $\mathrm{P}_{\text {in }}$ is the solar constant approximately equal to $100 \mathrm{mWcm}^{-2}$ under AM1.5 conditions.

As a result of several decades of intense research on PV devices, the first parameter $\mathrm{V}_{\text {oc }}$ is approaching its highest values. For example, $\mathrm{GaAs} / \mathrm{Al}_{\mathrm{x}} \mathrm{Ga}_{(1-\mathrm{x})} \mathrm{As}$ based solar cells have produced $\mathrm{V}_{\mathrm{oc}} \sim 1175 \mathrm{mV}$ (Dharmadasa et al., 2005, 2006, 2011) reaching the highest achievable values for this parameter from a single device. The FF is also reaching mid $80 \%$ for high efficiency devices. Since these two parameters are reaching their highest possible values, the only parameter that can be considerably

* Corresponding author (dharme@shu.ac.uk) 
improved is the $\mathrm{J}_{\mathrm{sc}}$. In order to increase this parameter, the photon harvesting within a given device must be improved. This paper addresses how the photons could be captured effectively from both direct sunlight and the surrounding heat energy, and how to combine impact ionization and impurity PV effect within one device, in order to maximise $\mathrm{J}_{\mathrm{sc}}$ and hence increase the overall solar energy conversion efficiency. In order to highlight the accuracy of the new concepts, independently verified experimental results from the main author's group are presented in relevant sections. However, all concepts discussed in this paper can be used to effectively harvest photons in PV solar cells based on any suitable solar energy material, when the bandgaps are engineered appropriately.

\section{EXPERIMENTAL RESULTS AND THEORETICAL DISCUSSION}

This section examines the photons available in the solar spectrum and how these can be efficiently absorbed and utilzed to create charge carriers within the solar cell. In addition, the solar cells are also exposed to IR radiation from their surroundings, as well as the heat energy created within the cells during the day time. These IR radiations could also be utilzed in this quantum absorption PV process, if the solar cells are designed and manufactured carefully to capture most of the photons with different energy, within one device. The combination of the absorption of major part of the solar spectrum and the use of some IR radiation from surroundings and heat created within the cells could contribute considerably to enhancement of $\mathrm{J}_{\mathrm{sc}}$.

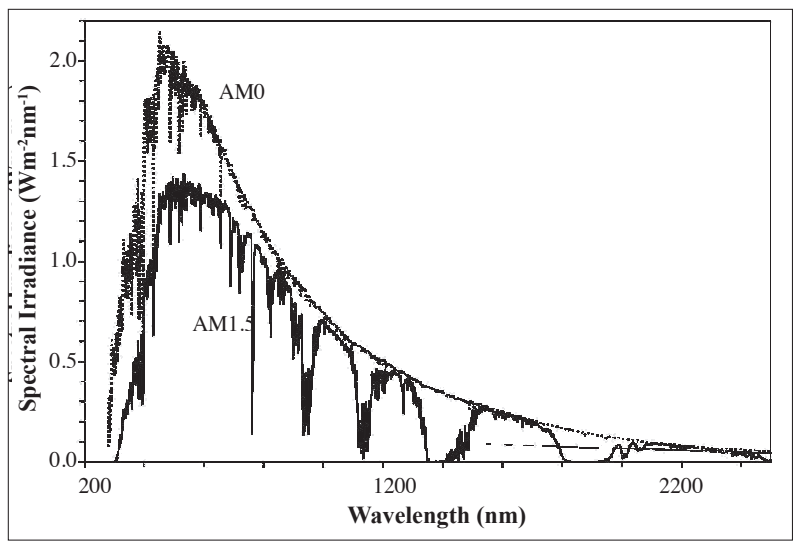

Figure 1: Approximate shape of the solar spectrum under AM1.5 condition. The shape of the spectrum before entering the air atmosphere (AM0 condition) is also shown for comparison (NREL website).

\section{Harvesting the majority of photons available in the solar spectrum}

The wavelength distribution of photons present in the solar spectrum is well documented in literature (NREL) and a part of this data is shown in Table 1, for AM1.5 conditions. The first and the second columns show the wavelength distribution of photons and the rate of energy falling on a unit area of the Earth's surface. The wavelength varies from the UV $(280 \mathrm{~nm})$ to the infrared end $(4000 \mathrm{~nm})$, and Figure 1 graphically shows the energy distribution as a function of wavelength for both AM1.0 and AM1.5 conditions.

Table 1: Solar energy falling on the Earth's surface as a function of wavelength and the calculated maximum $\mathrm{J}_{\mathrm{sc}}$ values possible by absorption of all photons in a PV device.

\begin{tabular}{cccc}
\hline $\begin{array}{c}\text { Wavelength } \\
(\mathrm{nm})\end{array}$ & $\begin{array}{c}\text { AM1.5 solar } \\
\text { power }\left(\mathrm{Wm}^{-2}\right)\end{array}$ & $\begin{array}{c}\text { Number of } \\
\text { photons } \\
\left(\mathrm{m}^{-2} \mathrm{~s}^{-1} \mathrm{~nm}^{-1}\right)\end{array}$ & $\begin{array}{c}\text { Maximum } \mathrm{J}_{\mathrm{sc}} \\
\left(\mathrm{mAcm}^{-2}\right)\end{array}$ \\
\hline 280.0 & $2.5361 \times 10^{-26}$ & $3.41 \times 10^{-6}$ & 0.0 \\
281.0 & $6.1253 \times 10^{-24}$ & $1.47 \times 10^{-3}$ & 0.0 \\
378.0 & $6.0314 \times 10^{-1}$ & $1.09 \times 10^{18}$ & 1.1 \\
379.0 & $5.2616 \times 10^{-1}$ & $9.52 \times 10^{17}$ & 1.2 \\
901.0 & $5.6162 \times 10^{-1}$ & $2.77 \times 10^{18}$ & 30.8 \\
902.0 & $6.2500 \times 10^{-1}$ & $3.12 \times 10^{18}$ & 30.9 \\
903.0 & $6.4483 \times 10^{-1}$ & $3.33 \times 10^{18}$ & 31.0 \\
3990.0 & $7.3894 \times 10^{-3}$ & $1.46 \times 10^{17}$ & 56.8 \\
3995.0 & $7.2263 \times 10^{-3}$ & $9.62 \times 10^{16}$ & 56.8 \\
4000.0 & $7.1199 \times 10^{-3}$ & $4.78 \times 10^{16}$ & 56.8 \\
\hline
\end{tabular}

The data in column two shows the rate of solar energy falling on the Earth's surface under AM1.5 conditions. This data allows the calculation of the number of photons falling on the Earth's surface (energy/energy of a photon $=\mathrm{E} / \mathrm{hf}$ ), and these are presented in column three. Assuming each photon is absorbed and one electron is created, the maximum current produced by a unit area (number of electrons $\times$ electronic charge) can be evaluated. Starting from the UV end and integrating the total current, the maximum possible current density $\left(\mathrm{J}_{\mathrm{sc}}\right)$ can be evaluated for complete absorption of photons in the solar spectrum.

These $\mathrm{J}_{\text {sc }}$ values are shown in the last column of Table 1 and are plotted in Figure 2, as a function of the wavelength and the corresponding energy bandgap of the semiconductor, which can be used to fabricate a $p-n$ homo-junction. 


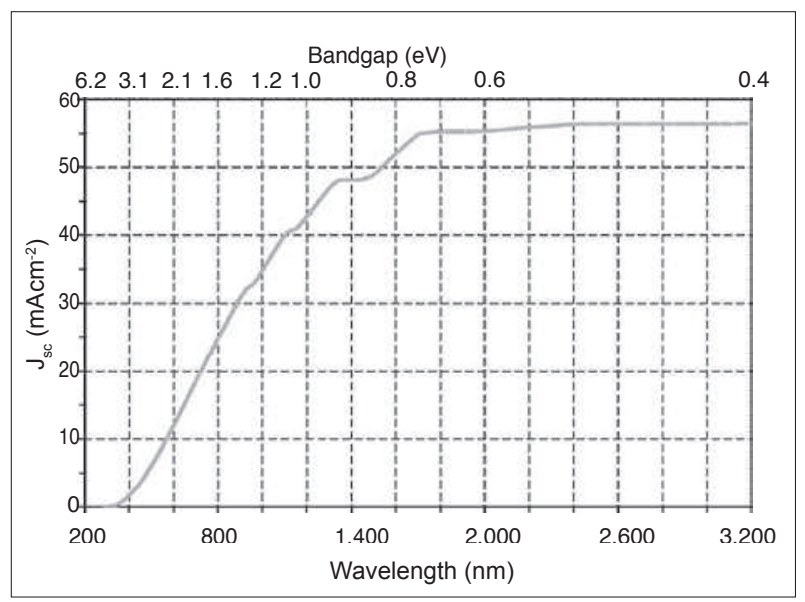

Figure 2: The maximum possible $\mathrm{J}_{\mathrm{sc}}$ values achievable as a function of wavelength / energy gap when each photon creates one e-h pair, in the absence of all loss mechanisms such as reflections at the surface and recombination within the device structure.

Figure 2 shows the maximum possible current density values that can be achieved by absorption of all photons in the solar spectrum. These values are based on each photon creating a single electron and assume that there are no losses due to reflections at the surface and recombination processes. For example, the maximum $\mathrm{J}_{\mathrm{sc}}$ for $\operatorname{CdTe}\left(\mathrm{E}_{\mathrm{g}}=1.45 \mathrm{eV}\right)$, GaAs $\left(\mathrm{E}_{\mathrm{g}}=1.43 \mathrm{eV}\right)$ and $\mathrm{Si}\left(\mathrm{E}_{\mathrm{g}}=1.10 \mathrm{eV}\right)$ based homo-junctions are $\sim 27, \sim 29$ and $\sim 41 \mathrm{mAcm}^{-2}$, respectively. If all the photons up to $0.50 \mathrm{eV}$ can be absorbed in one device, the ideal $\mathrm{J}_{\mathrm{sc}}$ value can rise up to $\sim 56 \mathrm{mAcm}^{-2}$. These values are shown in Table 2 with their corresponding semiconductors and respective $\mathrm{E}_{\mathrm{g}}$ values.

Table 2: Maximum possible $\mathrm{J}_{\mathrm{sc}}$ values from ideal homo-junctions based on different semiconductors when there are no losses due to reflection of light and recombination of charge carriers. These maximum $\mathrm{J}_{\mathrm{sc}}$ values are obtained from the theoretically calculated graph shown in Figure 2.

\begin{tabular}{lccc}
\hline $\begin{array}{l}\text { Material used in a } \\
\text { homo-junction }\end{array}$ & $\begin{array}{c}\text { Bandgap } \\
(\mathrm{eV})\end{array}$ & $\begin{array}{c}\text { Corresponding } \\
\text { wavelength } \\
(\mathrm{nm})\end{array}$ & $\begin{array}{c}\mathrm{J}_{\mathrm{sc}} \\
\left(\mathrm{mAcm}^{-2}\right)\end{array}$ \\
\hline CdTe (direct bandgap) & 1.45 & 855 & $\sim 27$ \\
GaAs (direct bandgap) & 1.43 & 867 & $\sim 29$ \\
Si (in-direct bandgap) & 1.10 & 1127 & $\sim 41$ \\
InN, GaSb (direct bandgap) & $\sim 0.72$ & 1720 & $\sim 55$ \\
Ge & 0.67 & 1850 & $\sim 56$ \\
$\mathrm{PbS}$, InAs & 0.36 & 3440 & $\sim 57$ \\
\hline
\end{tabular}

The current density values given in Table 2 as a function of energy bandgaps are possible only under ideal conditions, but the $\mathrm{V}_{\mathrm{oc}}$ value depends on the bandgap of the semiconductor. Since the upper limit of the $\mathrm{V}_{\text {oc }}$ is controlled by the value of the bandgap, $\mathrm{V}_{\mathrm{oc}}$ decreases with increasing $\mathrm{J}_{\mathrm{sc}}$. To optimize the efficiency, the product $\mathrm{V}_{\mathrm{oc}} \times \mathrm{J}_{\mathrm{sc}}$ should be maximized. Therefore in order to keep high $\mathrm{V}_{\mathrm{oc}}$ values and obtain the largest possible $\mathrm{J}_{\mathrm{sc}}$ values, the PV devices must be designed to produce the largest potential barrier heights, as well as the absorption of all the photons within one device. The way forward is the next generation of PV devices based on graded bandgap multi-layer thin film solar cells.

\section{Graded bandgap multi-layer solar cells}

The new design proposed (Dharmadasa, 2005) and experimentally tested in 2005 (Dharmadasa et al., 2005) for absorption of UV, visible and IR radiation within one device is given in Figure 3. The main features of this design include the use of a wide bandgap p-type semiconductor as the window material, gradual reduction of the energy bandgap and gradual conversion from p-type to n-type electrical conduction from the front to the back of the device. The smallest bandgap material limits the value of $\mathrm{V}_{\mathrm{oc}}$ achievable and therefore it is sensible to keep this value at about $1.43 \mathrm{eV}\left(\mathrm{E}_{\mathrm{g}}\right.$ of GaAs).

The large bandgap in the front of the solar cell helps in creating a steep slope (strong internal electric field) in the solar cell structure in order to effectively separate photo-generated charge carriers. The low-resistive ohmic contacts to the p-type semiconductor at the front and the n-type semiconductor at the back provide effective collection of charge carriers and allow efficient passage through an external load creating useful DC power.

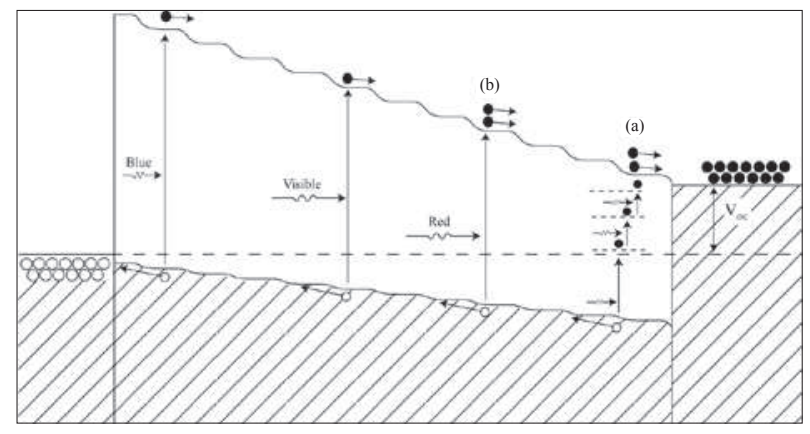

Figure 3: The energy band diagram of the solar cell under illumination and open circuit condition. Note the reduced R\&G process by separating photo-generated charge carriers by $\sim 3 \mu \mathrm{m}$ solar cell device thickness. 
Furthermore, in order to spread the depletion region throughout the device width, the doping concentration of the end materials should be as low as $\sim 10^{15} \mathrm{~cm}^{-3}$ (Sze, 1981). Then the whole device becomes PV active with a steep slope or a strong internal electric field present throughout the width of the device.

The structure shown in Figure 3 gradually absorbs $\mathrm{UV}$, visible and IR as the solar radiation penetrates through the device. The direct bandgap semiconducting materials with a high absorption coefficient, such as GaAs and CdTe need only a $3 \mu \mathrm{m}$ layer to absorb the whole spectrum. Therefore the distance between the front and the back ohmic contacts could be limited to approximately $3 \mu \mathrm{m}$, utilizing a small amount of expensive semiconducting materials. The animations to show PV action of this device can be found in the web: [http://www.apsl.org.uk/dharmes\%20blog.html(tunnel junction file)].

\section{Contributions from the impurity photovoltaic effect}

The most energetic blue-end photons are absorbed in the wide bandgap, front semiconducting material layer (Figure 3). As the light gradually travels through the device, the photons will be effectively absorbed in the order of UV, visible and IR, thereby minimizing the thermalisation effect. This effect reduces the production of heat within the device and is an effective cooling mechanism for PV cells. All electrons and holes created by photons are instantaneously separated without any hindrance, towards the two ohmic contacts due to the presence of a strong electric field throughout the device.

The IR photons are transmitted towards the back of the solar cell without absorption due to their low photon energies. In the vicinity of the interface at GaAs substrate/ $\mathrm{Al}_{\mathrm{x}} \mathrm{Ga}_{(1-\mathrm{x})} \mathrm{As}$, the density of native defects is high. Making use of these numerous native defect levels (Goodridge, 1990; Adachi, 1993), the IR radiation could produce e-h pairs using multi-absorption pathways as shown in process (a) in Figure 3. Promoted electrons do not relax back, since the created holes are rapidly transferred to the ohmic contact at the front. Therefore, this is an effective electron upward-pumping mechanism created due to the shape of the energy band diagram, and making beneficial use of native defects in the materials. When this process is taking place under illuminated conditions, the contributions to the detrimental recombination process or downward-pumping of electrons is inhibited. This is another indirect advantage of this particular device structure and the experimental results to date have confirmed this effect. The measurements of I-V curves under dark and illuminated conditions provide another useful parameter, $n$ (ideality factor), to observe this effect. Table 3 shows these experimental results and clearly demonstrates that the ideality factor $n$ has reduced under illumination. This is a good indication of the dominance of the upwards electron pumping process taking place, and inhibiting the detrimental downward electron pumping process (recombination).

Table 3: The ideality factors for $\mathrm{Al}_{\mathrm{x}} \mathrm{Ga}_{(1-\mathrm{x})} \mathrm{As}$ based graded bandgap solar cells under dark and illuminated conditions, showing reduced recombination process under illumination.

\begin{tabular}{lccccc}
\hline Solar cell number & 1 & 2 & 3 & 4 & 5 \\
\hline $\begin{array}{l}n \text { value under dark } \\
\text { conditions }\end{array}$ & 1.41 & 1.50 & 1.68 & 1.84 & 2.26 \\
$\begin{array}{l}n \text { value under illuminated } \\
\text { conditions }\end{array}$ & 1.13 & 1.15 & 1.22 & 1.14 & 1.91 \\
\hline
\end{tabular}

The impurity PV effect therefore effectively uses the naturally existing impurity levels, to this new device's advantage in converting IR photons present in the solar spectrum into useful charge carriers. The measurements of responsivity as a function of wavelength also show the collection of current in the IR region confirming the presence of impurity PV effect in these devices. These results are shown in Figure 4 with clear evidence of the contribution from IR radiation.

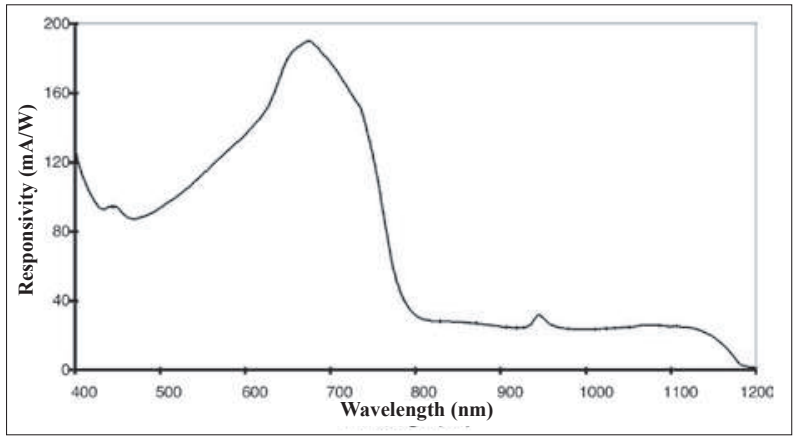

Figure 4: A typical responsivity versus wavelength curve measured for graded bandgap devices. Note the positive response in the IR region up to $\sim 1200 \mathrm{~nm}$.

\section{Contributions from surroundings}

The PV devices are always surrounded by IR radiation present in the surroundings. This radiation can also 
be utilzed to enhance charge carriers, using impurity PV effect described above. As shown in process (a) in Figure 3, e-h pairs can be produced by the multiabsorption process.

In order to test this effect experimentally, the new devices have been measured in complete darkness and the results are shown in Figure 5. The graded bandgap devices fabricated with well researched $\mathrm{GaAs} / \mathrm{Al}_{\mathrm{x}} \mathrm{Ga}_{(1-\mathrm{x})} \mathrm{As}$ system produced $\mathrm{V}_{\mathrm{oc}}$ values in the range of $650-900 \mathrm{mV}$ in complete darkness, showing the contribution from the impurity PV effect utilizing heat energy from the surroundings (Dharmadasa et al., 2011).

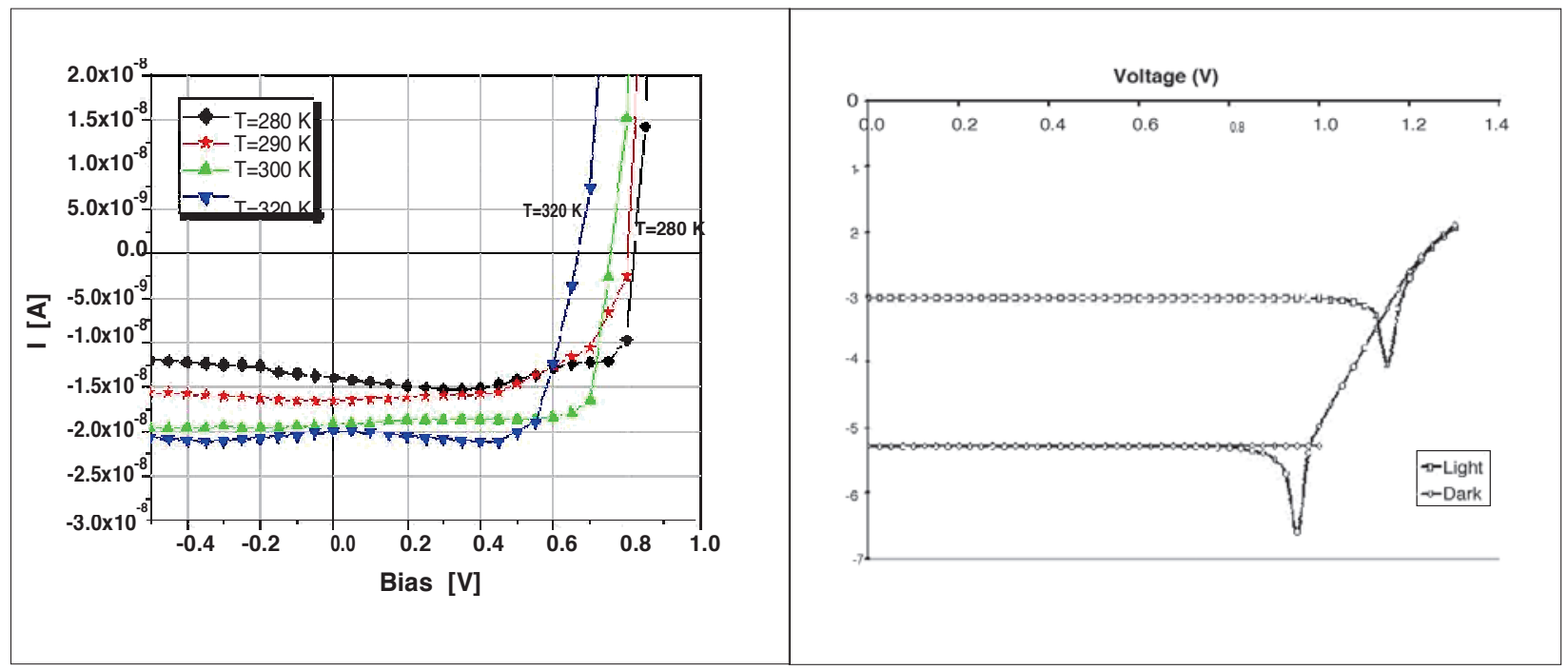

Figure 5: Linear-linear I-V curves measured under complete darkness and log-linear I-V curves measured under dark and AM1.5 illuminated conditions for graded bandgap devices. Note the observation of $\mathrm{V}_{\text {oc }}$ in the range $650-900 \mathrm{mV}$ in complete darkness.

\section{Contributions from impact-ionization}

The device shown in Figure 3 is designed to incorporate impact ionization for enhanced charge carrier generation. The UV photons are absorbed in the front of the device, and the photo-generated electrons have a steep slope to accelerate them across the thickness of the device. As the bandgap becomes smaller towards the back of the device, the hot-electrons created in the front of the device can accelerate and create additional charge carriers by impact-ionization. These possible band-toband transitions are shown as the process (b) in Figure 3. The probability of this process can be low, since the hot carriers should have excess energy equal to the band gap of the material at that point.

The most effective impact ionizations arise from the combination of impurity PV effect and impact-ionization. As described earlier, both IR radiation from the solar spectrum and the surroundings promote electrons from the valence band to numerous defect levels.

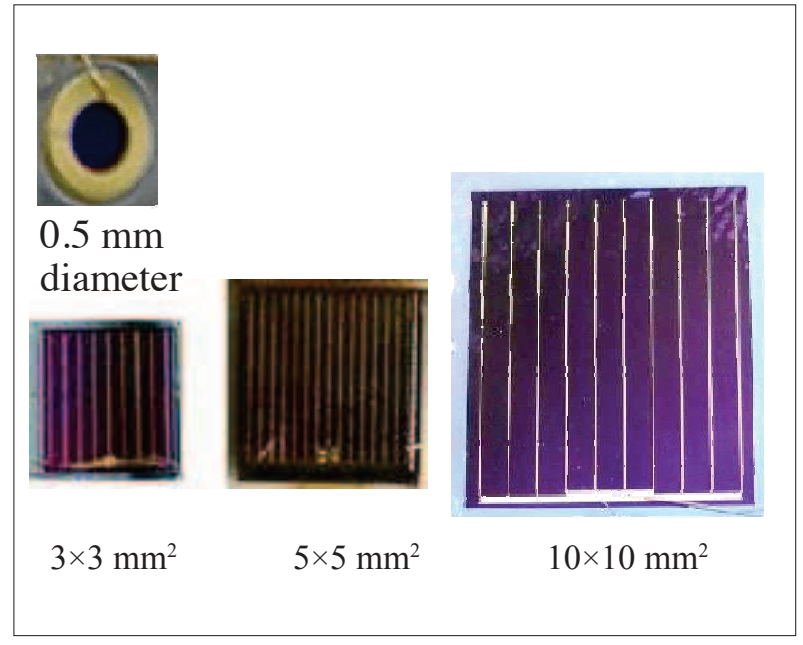

Figure 6: Photograph of solar cells fabricated with different dimensions to test the effect of the scaling up process. The solar cell parameters remain constant up to the size $10 \times 10 \mathrm{~mm}^{2}$. 
Most of the electrons created in the front of the cell under solar illumination are then capable of promoting these electrons from defect levels to the conduction band. This could take place as an avalanche effect, as shown in the process (a) in Figure 3.

The capability of complete absorption of the solar spectrum and the combination of impurity PV effect together with impact-ionization could produce large $\mathrm{J}_{\mathrm{sc}}$ values when the solar cell is fabricated with all the required specifications. Work is continuing to observe experimental evidence for impact ionization in these devices.

\section{Summary of experimental results to date}

The solid state physics principles incorporated together in order to create high potential barriers and hence establish a strong internal electric field within the device have been tested in this study. A p-type and wide bandgap semiconductor has been used in this device instead of traditional n-type window material. The window material is $\mathrm{Al}_{\mathrm{x}} \mathrm{Ga}_{(1-\mathrm{x})}$ As alloy with $\mathrm{E}_{\mathrm{g}} \sim 2.00 \mathrm{eV}$. The bandgap of the absorber layer was gradually increased by increasing the $\mathrm{Al}$ content in the material towards the front of the device. The narrowest $\mathrm{E}_{\mathrm{g}}$ is equal to $1.43 \mathrm{eV}$; the bandgap of GaAs substrate used to grow the device structure.

The advantages of this structure were shown by the first experimental test using MOVPE grown GaAs/ $\mathrm{Al}_{\mathrm{x}} \mathrm{Ga}_{(1-\mathrm{x})} \mathrm{As}$ system (Dharmadasa et al., 2005). The parameters as measured in six different labs including National Renewable Energy Laboratory (NREL) in the United States for this first fabrication were:

$\mathrm{V}_{\mathrm{oc}} \sim 1175 \mathrm{mV}, \quad \mathrm{J}_{\mathrm{sc}} \sim(11-12) \mathrm{mAcm}^{-2}, \quad \mathrm{FF} \sim(0.82-$ $0.87), \quad \eta=(10-12) \%$

The $\mathrm{V}_{\mathrm{oc}}$ and FF have achieved the highest possible values, but the $\mathrm{J}_{\mathrm{sc}}$ for the first growth was not high as expected. The $\mathrm{V}_{\mathrm{oc}}^{\mathrm{sc}}=1175 \mathrm{mV}$ value exceeds the highest reported value of $\left(\mathrm{V}_{\mathrm{oc}}=1047 \mathrm{mV}\right)$ to date (Green et al., 2005; Takahashi et al.) for a $\mathrm{GaAs} / \mathrm{Al}_{\mathrm{x}} \mathrm{Ga}_{(1-\mathrm{x})} \mathrm{As}$ single device.

In order to test the effect of scaling-up on the device parameters, solar cells of dimensions $0.5 \mathrm{~mm}$ diameter, $3 \times 3 \mathrm{~mm}^{2}, 5 \times 5 \mathrm{~mm}^{2}$ and $10 \times 10 \mathrm{~mm}^{2}$ devices have been fabricated. But their parameters remained the same as expected from epitaxially grown $\mathrm{GaAs} / \mathrm{Al}_{\mathrm{x}} \mathrm{Ga}_{(1-\mathrm{x})} \mathrm{As}$ system. The devices fabricated with different sizes are shown in Figure 6.
The expected band diagram for this cell is as in Figure 3. However, the EBIC and SIMS results (Dharmadasa, 2012) indicated that the structure of the experimentally produced devices was different (Figure 7). The doping concentrations at the two ends were high in the region of $10^{18} \mathrm{~cm}^{-3}$, and hence the resultant energy bands were almost flat reducing the current collection. However, the middle part with the internal electric field acts as a solar cell with a reduced thickness creating the features expected from the new design and therefore producing excellent values for $\mathrm{V}_{\mathrm{oc}}$ and $\mathrm{FF}$.

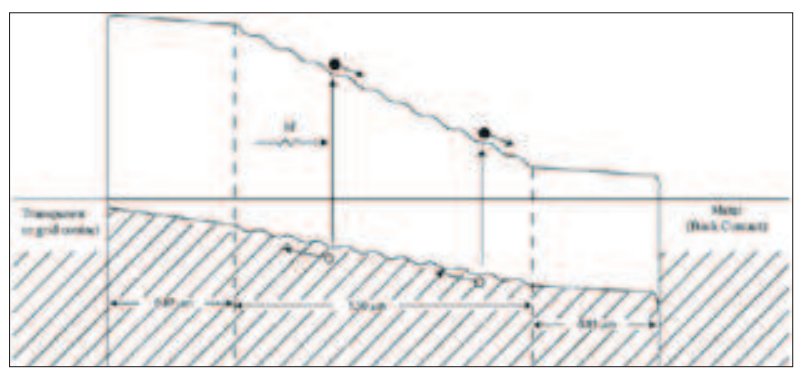

Figure 7: The band diagram of the device fabricated during first growth due to high doping concentrations at both ends of the structure.

The second MOVPE growth reducing the n-type doping concentration $(\mathrm{Si})$ at the rear of the device from $\sim 10^{18}$ to $\sim 10^{15} \mathrm{~cm}^{-3}$ gave the following overall improved device performance:

$\mathrm{V}_{\mathrm{oc}} \sim 900 \mathrm{mV}, \quad \mathrm{J}_{\mathrm{sc}} \sim(22-26) \mathrm{mAcm}^{-2}, \quad \mathrm{FF} \sim(0.82-$ $0.87), \quad \eta=(18-20) \%$

This improvement in the doping concentration at the rear of the device provides a better shape of the energy band diagram for the expected device (Figure 8). Therefore the device parameters have improved considerably. This improvement can be observed clearly in quantum efficiency measurements as shown in Figure 9. The cut-off frequency at the redend was $\sim 740 \mathrm{~nm}$ for the first set of devices indicating loss in the IR region. However, the reduction of silicon doping at the back has extended the depletion region towards GaAs substrate and improved this situation. For the improved second batch of devices, the cut-off wavelength is $\sim 870 \mathrm{~nm}$, corresponding to the bandgap of GaAs (1.43 nm). 
The reduction of the high carbon doping in the front from $\sim 10^{18}$ to $\sim 10^{15} \mathrm{~cm}^{-3}$ is not possible from MOVPE method, due to the uncontrollable presence of background carbon in the reactor. Therefore, this doping optimisation should be carried out using a growth technique like MBE in order to fullfill this requirement.

It should be noted that the $\mathrm{V}_{\mathrm{oc}}$ has reduced from $\sim 1175 \mathrm{mV}$ in the first fabrication to $\sim 900 \mathrm{mV}$ during the second fabrication. Although this is not desirable for devices, this is a strong indication of the validity of the Fermi level pinning at different defect levels in the GaAs system, very similar to those observed for CdTe

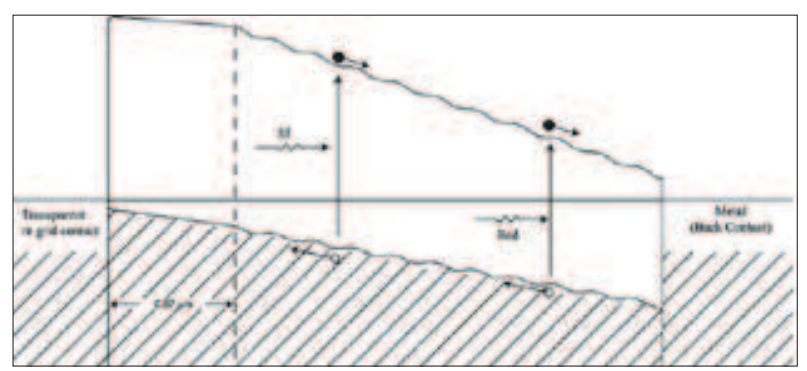

Figure 8: Energy band diagram of the improved device with lower Si doping at the rear of the solar cell.
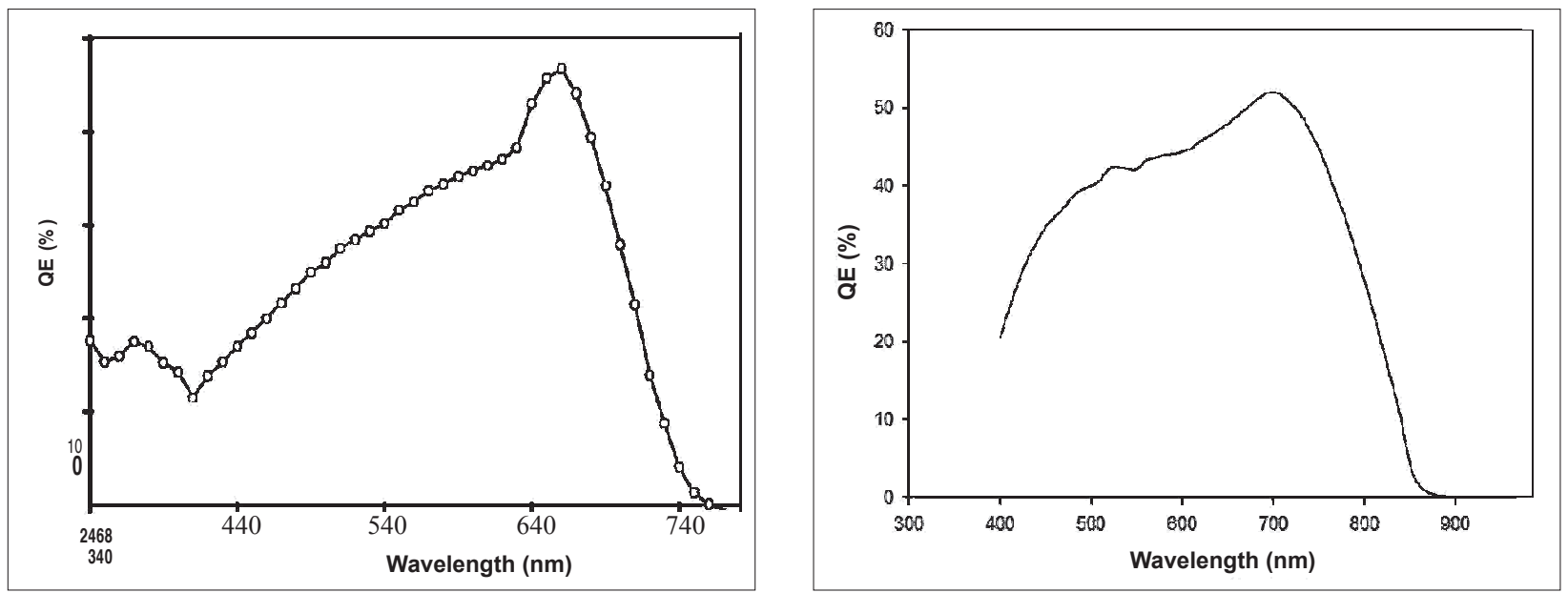

Figure 9: Quantum efficiency curves measured for devices fabricated from the first and the second growth. Losses in both blue and red ends are evident for the first set of devices. The improvement of silicon doping level at the back of the device has considerably improved the collection in the red end by shifting the cut-off wavelength from $\sim 740 \mathrm{~nm}$ to $\sim 870 \mathrm{~nm}$.

(Dharmadasa et al., 2002) and CIGS (Dharmadasa et al., 2008; Dharmadasa, 2009a,b) solar cells. Work is continuing on III-V compound based devices to explore this phenomenon and further improve the efficiency of this device.

\section{CONCLUSIONS}

The work presented in this paper draws several important conclusions.

The positive results of graded bandgap solar cells based on p-type window materials are demonstrated. The highest reported $\mathrm{V}_{\mathrm{oc}} \sim 1175 \mathrm{mV}$ together with highest achievable FF $\sim(0.82-0.87)$ values have been experimentally observed.

Impurity PV effect and impact ionization were theoretically incorporated in these devices at the design stage, and the contribution from impurity PV effect has been experimentally observed. Therefore, these types of solar cells have two inputs to create charge carriers as shown in Figure 10. These solar cells were observed to absorb both UV and visible light in addition to IR from the light and the surroundings to generate e-h pairs within one cell. The graded bandgap multi-layer device is therefore capable of producing high solar cell parameters $\left(\mathrm{V}_{\mathrm{oc}}, \mathrm{J}_{\mathrm{sc}}\right.$ and $\left.\mathrm{FF}\right)$ once the front doping concentrations have been optimized. 
The maximum current density values in the absence of surface reflections, recombination and transmission losses can be as high as $56 \mathrm{mAcm}^{-2}$. As shown in this paper, both the impurity PV effect and the impactionization have been incorporated and their contributions can be substantial. Therefore by carefully engineering the materials and processing these devices, higher $\mathrm{J}_{\mathrm{sc}}$ values and hence overall high efficiencies can be achieved.

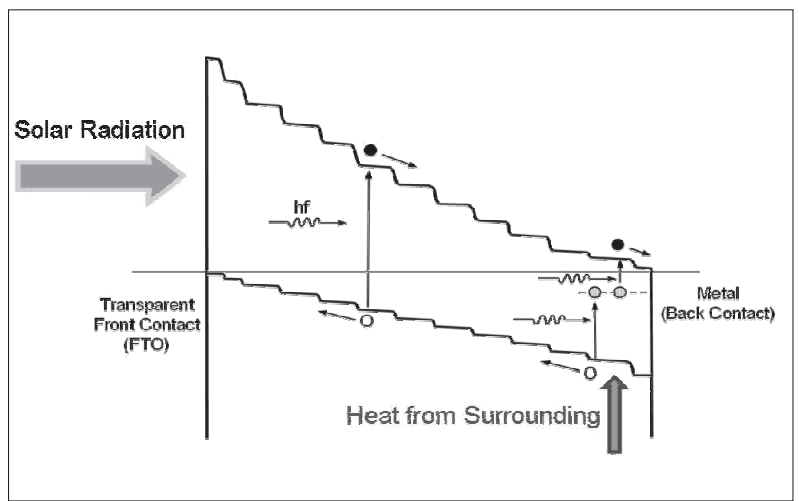

Figure10: Schematic diagram showing the two energy inputs available to this device structure. When placed in complete darkness, the device still produces PV activity using heat energy from the surroundings due to impurity PV effect.

\section{Acknowledgement}

Authors would like to gratefully acknowledge the contributions from Dr John Roberts, Dr Geoff Hill, Dr Gavin Tolan, Mr Osama El Sheriff, Dr K. Mahanama, Prof. Hari Reehal, Dr Seigo Ito, Dr Paul Liska, Prof. Michael Grätzel and Prof. Ayodhya Tiwari to this work by materials growth, device fabrication and device characterization.

\section{REFERENCES}

1. Adachi S. (1993). Properties of Aluminium Gallium Arsenide, EMIS Data Reviews Series, No. 7. INSPEC, London, UK.
2. Dharmadasa I.M. (2005). Third generation multilayer tandem solar cells for achieving high conversion efficiencies. Solar Energy Materials and Solar Cells 85: $293-300$.

3. Dharmadasa I.M. (2009a). Fermi level pinning and effects on $\mathrm{CuInGaSe}$ based thin film solar cells. Semiconductor Science and Technology 24: 055016 - 055025.

4. Dharmadasa I.M. (2009b). Latest developments in CdTe, $\mathrm{CuInGaSe}_{2}$ and $\mathrm{GaAs} / \mathrm{AlGaAs}$ thin film PV solar cells. Current Applied Physics 9(2): e2 - e6.

5. Dharmadasa I.M. (2012). Advances in Thin Film Solar Cells.Pan Stanford Publishing Ltd., Singapore.

6. Dharmadasa I.M., Samantilleke A.P., Young J. \& Chaure N.B. (2002). New ways of development of glass/conducting glass/CdS/CdTe/metal thin film solar cells based on a new model. Semiconductor Science and Technology 17: 1238 -1248 .

7. Dharmadasa I.M., Roberts J.S. \& Hill G. (2005). Third generation multi-layer graded bandgap solar cells for achieving high conversion efficiencies - II. Solar Energy Materials and Solar Cells 88: $413-422$.

8. Dharmadasa I.M., Tolan G.J., Roberts J.S., Hill G., Ito S., Liska P. \& Grätzel M. (2006). The reproducibility, uniformity and scalability of multi-layer graded bandgap solar cell structures based on GaAs/AlGaAs system, Proceedings of the $21^{\text {st }}$ EU Photovoltaic Conference, Dresden, Germany, pp. $257-262$.

9. Dharmadasa I.M., Chaure N.B., Samantilleke A.P. \& Hassan A. (2008). Multi fermi level pinning at metal/ $\mathrm{Cu}(\mathrm{InGa})(\mathrm{SeS})_{2}$ interfaces. Solar Energy Materials and Solar Cells 92(8): 923 - 928.

10. Dharmadasa I.M., Elsherif O. \& Tolan G.J. (2011). Solar cells active in complete darkness. Journal of Physics: Conference Series 286: 012041, doi:10.1088/1742$6596 / 286 / 1 / 012041$.

11. Goodridge I.H. (1990). Properties of Gallium Arsenide, 2nd edition, EMIS Data Reviews Series, No. 2. INSPEC, London, UK.

12. Green M.A., Emery K., King D.L., Igari S. \& Warta W. (2005). Solar cell efficiency tables (version 37). Progress in Photovoltaics: Research and Applications 19: 84 - 92.

13. National Renewable Energy Laboratory (NREL). http:// rredc.nrel.gov/solar/spectra/am1.5/, Accessed June 2011.

14. Sze S.M. (1981). Physics of Semiconductor Devices, $2^{\text {nd }}$ Edition. John Wiley \& Sons, New York, USA.

15. Takahashi K., Yamada S. \& Unno T., U.D.C. 621.383.51:523.9-7:[546.681'62'19: 546. 681'19] 